\title{
A Renewable Energy Joint Strategy for the Implementation of Local Action Plans for Renewable Energy
}

\author{
G. Casano and S. Piva* \\ ENDIF ENgineering Department In Ferrara, Università di Ferrara, Ferrara, Italia \\ Email: stefano.piva@unife.it
}

\begin{abstract}
As a baseline for the elaboration of useful instruments to increase the utilization of Renewable Energy in the cities, we present a Renewable Energy Joint Strategy (REJS), as proposed by the Partners of the European Project "Cities on Power". It constitutes a general guideline for public authorities on how to act to fulfil the provisions on Renewable Energy of the "Europe 2020 Strategy for growth and jobs" and on how to promote and make the best use of renewable energy. A REJS should face all needs of the different stake-holders and be able to offer a balanced approach to their satisfaction. Some preliminary activities made it possible to obtain a clear vision regarding to infrastructural, environmental and technological constrains and assess the potential of Renewable Energy Sources (RESs) in the specific local areas. The REJS covers the three fundamentals of EU energy policy (sustainability, security of supply and competitiveness) and is consistent with the long-term EU decarbonisation scenarios. The REJS is detailed through the following issues: General policy approach, Financial support, Administrative procedures, RESs in distributed power production and Smart Grids, RESs in Heating and Cooling and electricity, Sustainability, Regional and international dimensions, Technology development, Participation.
\end{abstract}

Keywords: Renewable energy, Local action plans, Joint strategy, Heating and cooling.

\section{INTRODUCTION}

Most of the EU inhabitants lives in cities, most of the EU energy is consumed in cities and also most of the EU's greenhouse emissions comes from urban areas. For achieving national and EU targets of climate protection, reducing pollution, increasing the energy independence, it will be necessary a deep involvement of cities and specifically the adoption of strict determinations to foster the development of renewable energy. In the Project called "Cities on Power" one of the instruments proposed by the Partners to increase the utilization of Renewable Energy Sources (RESs) in the cities is the implementation and endorsement of Local Action Plans (LAPs in the following) for Renewable Energy. For the elaboration of their LAPs the Partners developed a Renewable Energy Joint Strategy (REJS in the following) [1] pointing out the strategic axes of activities with respect to the promotion of the renew-able energy in the urban context. As such it reflects the approach of the Partners to the preparation of the LAPs for Renewable Energy. At the same time it constitutes a general guideline for public authorities on how to act to fulfil the pro-visions on renewable energy of the "Europe 2020 Strategy for growth and jobs" and on how to promote and make the best use of Renewable Energy Sources (RESs in the following). The target groups of this REJS are thence local politicians, decision makers and high-rank officials that take part in any process of preparing energy policies in local administra- tions involved in these activities. Therefore, in addition to the Partners also others public authorities can use it and receive a benefit.

By analyzing the process of production, management and utilization of RESs, in the cities, beside local politicians and decision makers further groups of stakeholders are relevant, in particular investors and final energy consumers. Obviously, different stakeholders show different needs. A REJS should face all these needs and be able to offer a balanced approach to their satisfaction.

A REJS derives from preliminary activities that make it possible to obtain a clear vision, useful for a strategy on RESs, outline the options on RESs having regard to infrastructural, environmental and technological constraints and assess the potential of RESs in the specific local areas. These results are thence the baseline of a Joint Strategy, allowing the definition of targets and regulatory measures of urban planning and building codes for a more intensive recourse to RESs. These steps are summarized as follows:

1) Individuation of the Policy Context: this was obtained through a SWOT analysis of the regulatory framework at EU, national, regional and local levels; it guarantees that the local assumptions of the REJS will be in line with the strategies of higher level (regional, national, European) and ensures the validity of the strategy in the context of regional, national and EU obligations. This because it is evident that regional, national and EU policies are the context where the Joint Strate- 
gy for RESs requires to be developed.

2) Individuation of the RESs support schemes: this also was obtained through a SWOT analysis of the financial incentives; it guarantees a clear identification of the different instruments able to promote a deep rooting of the RESs in the social and economical structures, in a context where the financial schemes designed to support the development of RES are many and differentiated.

3) Identification and assessment of resources and potential of the different RESs in the local context, in particular for urban areas: this was obtained through a comparative analysis; in this step, beside a review of the available information on the resources in the area, an useful point is the production of maps of potential and availability of RESs. This is also helpful in individuating the infrastructural and environmental barriers to overcome.

4) Development of pilot projects for the renewable resources, which are at the same time differentiated and integrated / monitored on a common basis, in order to facilitate the inclusion of these innovative technologies, fruit of mutual trans-national endeavours, into the Local Action Plans.

5) Information and promotion activities useful for a rising awareness and participation in investments on RESs: this was obtained through a number of local activities of information and promotion. In fact, being aware of the role of Renewable Energy, allow the stakeholders to take actions to make informed energy choices.

The Project "Cities on Power" involves five expert institutions and four public authorities (City of Warsaw, Municipal Authorities of the provincial capital Klagenfurt, Province of Ravenna and Province of Torino) from four countries, the latter with the capacity to implement the results of the project in their political context. This group of public authorities shows also the will to develop and adopt Local action plans for renewable energy. This gives a deep significance to the activities because the experience acquired by the Partners in the implementation of the REJS could become relevant for the cross-fertilization of the results.

\subsection{EU renewable energy policy}

The promotion of Renewable Energy is a cornerstone in the EU's climate and energy strategy until 2020 as confirmed with the 20/20/20 targets for greenhouse gas reductions, energy efficiency and RES contained in the "Europe 2020 Strategy for growth and jobs" [2]. It is believed that RESs can provide various benefits:

- contribute to the environment and climate protection policy objectives,

- help to diversify the energy supply and lower the dependence on foreign suppliers,

- reduce exposure to the volatility of energy prices,

- contribute to technology development, regional growth and employment.

Moreover, over the last decade, while the price of fossil energy sources has gradually increased, the price of the production of energy from RESs has dropped steadily, at times even quite sharply.

As regards RESs the EU's legislative framework is laid down in the Renewable Energy Directive [3]; it includes specific measures and objectives for the three following sectors: electricity, biofuels and heating \& cooling. In particular Renewable Energy Directive sets an obligatory target of $20 \%$ renewable energy in gross final energy consumption as well as a $10 \%$ target for the share of renewable energy in transport for 2020 .
Figure 1 shows the trend of the share of energy from RESs in gross final consumption of energy in EU-28 during the period 2004-2013 and the final target at 2020. It is evident that the EU's trend is tending to the target. This means that the comprehensive and binding regulatory framework provided by the EU's Renewable Energy Directive is effective in driving forward the renewable energy development to achieve the targets that EU has set itself.

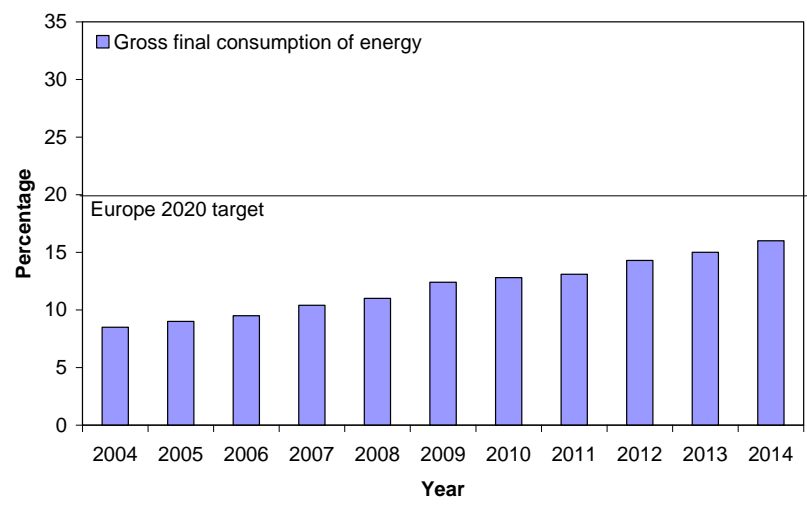

Figure 1. Share of energy from renewable sources in gross final consumption of energy, EU-28, 2004-2014 (Source Eurostat - Energy from renewable sources 2015)

It is also clear that the achievement of the EU's overall energy and climate policy targets necessarily requires stronger efforts towards energy saving and energy efficiency. Strong policies on energy efficiency and renewable energy are mutually reinforcing because a lower overall consumption allows reaching the RESs targets faster and at lower costs and the adoption of the energy saving strategies would help achieve the aims of the renewable energy policy.

Furthermore, the current targets for energy and climate embodied in the Europe 2020 Strategy [2] should be seen as interlinked and mutually reinforcing.

It is therefore appropriate to establish standalone targets for RESs in the context of possible targets for energy efficiency and climate mitigation.

It should be emphasized that the stimulation of an energy market of RESs through specific policies involves new specific challenges, some associated with the character of the energy sector, some specific to the introduction of RESs. The policy-makers and other involved stakeholders, in particular at the local level, need to be ready to drive the process and move the activities towards an increase of the share of RESs, while being able to control this growth.

\subsection{Cities and renewable energy joint strategy}

Even if recent significant programs, both at national and local level $[4,5]$ are available, characterized by placing energy savings and energy efficiency as their main priorities, there are still relatively few explicit local policies on renew-able energy.

However, on one hand it is important to explicitly highlight the RESs in urban planning, rather than insert them into other issues such as sustainability, climate change, clean transportation, and "green" or "eco" programs. A reduced final energy demand is important because enables the RESs [6] the satisfaction of a larger share of demand and this could grow the risk to overlook or to limit the potential of these energy sources.

On the other hand it is important to point out that RESs 
should be promoted only if they are environmental friendly. This means to consider:

- best available technologies,

- landscape attention,

- low emissions systems,

- low environmental impact on the natural resources,

- limited utilization of free lands.

In the massive introduction of RESs in cities a central role is played by cities and local authorities. It is well known that coverage targets with RESs can be established only at the national level. However, the capability to govern and guide the communities, to provide services and manage municipal resources, make the political mandate of the local governments the right instrument to stimulate and drive the implementation of RESs in the cities.

The production of regional, national and European policies, very often updated in these last times, needs to be driver with Local action plans. For this reason the Local action plans have to be structured so to be easily modified and updated in coordination with the higher level policies.

It may also be useful to examine the local plans developed in the immediate vicinity of the area under planning; in this way it will be possible to avoid possible differences, difficult to be understood by the final user, and to individuate possible trans-boundary issues.

For these reasons, the main purpose of a LAP is to examine the conditions that might be necessary for a further development of RESs at the local level. This must cover the three fundamentals of energy policy (sustainability, security of supply and competitiveness) consistently with the European scenario presented in the Renewable Energy Directive which points to a substantially increased share of RESs.

In accordance with the Renewable Energy Directive [3], a LAP also points to the need to ensure a cost-effective development of the RESs potential, as well as to ensure that their further expansion happens in line with the requirements for system stability and is consistent with other EU policies, notably climate mitigation, internal market, international cooperation and technology development and protection of the environment, including biodiversity.
A LAP is based on the rationale that a positive framework for the development of RESs is necessary due to a number of market failures or imperfections. These include elements like:

- the non-internalisation of negative externalities of conventional energy forms,

- the presence of subsidies for other non renewable energy forms (for instance cogeneration),

- imperfect market structures,

- regulatory barriers,

- the status of many renewable technologies as "infant industries" together with a significant inertia of the system,

- barriers related to information and public perception.

It is particularly appreciated the validity of the EU's current approach for a period when the RES will move from margin to centre of the stage and will be applied on a large scale, at least for the more mature technologies. A LAP therefore is intended to suggest a locally specified approach to the choice of forms and extent of policy interventions on RESs.

In Table 1 is shown, for EU28 during the period 20042013, the share of energy from RESs in gross final consumption of energy. Even if one Partner (Austria) can be recognized as a Pioneer in utilization of RESs for energy production, a general trend of growth is clearly visible. In this context this REJS is proposed also as the right instrument for a deeper local implementation of the general targets introduced by the EU directives.

\section{RENEWABLE ENERGY IN THE URBAN CONTEXT}

A common strategy for a growth of the Renewable Energy in the urban context like this REJS acts as a unifying and focusing element for the Local Action Plans to be developed according to the strategies of the Project "Cities on Power".

The aim of this REJS is to enable the Partners to center, at the local level, the European objectives of reducing consumption of fossil energy, increasing the efficient use of energy, progressively increasing the use of Renewable Energy and reducing greenhouse gas emissions.

Table 1. Share of energy (\%) from renewable sources in gross final consumption of energy, heating and cooling and in gross electricity consumption of energy, EU-28, 2004-2014 (Source Eurostat - Energy from renewable sources 2015)

\begin{tabular}{|c|c|c|c|c|c|c|c|c|c|c|c|}
\hline & 2004 & 2005 & 2006 & 2007 & 2008 & 2009 & 2010 & 2011 & 2012 & 2013 & 2014 \\
\hline \multicolumn{12}{|c|}{ Share of energy from RESs in gross final consumption of energy } \\
\hline Austria & 23.3 & 23.8 & 25.3 & 27.3 & 28.2 & 30.1 & 30.6 & 30.8 & 31.6 & 32.3 & 33.1 \\
\hline Germany & 5.8 & 6.7 & 7.7 & 9.1 & 8.6 & 9.9 & 10.5 & 11.4 & 12.1 & 12.4 & 13.8 \\
\hline Italy & 6.3 & 7.5 & 8.3 & 9.8 & 11.5 & 12.8 & 13.0 & 12.9 & 15.4 & 16.7 & 17.1 \\
\hline Poland & 6.9 & 6.9 & 6.9 & 6.9 & 7.7 & 8.7 & 9.2 & 10.3 & 10.9 & 11.3 & 11.4 \\
\hline EU-28 & 8.5 & 9.0 & 9.5 & 10.4 & 11.0 & 12.4 & 12.8 & 13.1 & 14.3 & 15.0 & 16.0 \\
\hline \multicolumn{12}{|c|}{ Share of energy from RESs for heating and cooling } \\
\hline Austria & 21.4 & 22.1 & 22.9 & 25.7 & 26.1 & 28.1 & 29.8 & 30.2 & 31.2 & 32.7 & 32.6 \\
\hline Germany & 6.3 & 6.8 & 6.9 & 8.3 & 7.4 & 9.2 & 9.8 & 10.5 & 10.4 & 10.6 & 12.2 \\
\hline Italy & 5.7 & 8.2 & 10.1 & 13.3 & 15.3 & 16.4 & 15.6 & 13.8 & 17.0 & 18.1 & 18.9 \\
\hline Poland & 10.2 & 10.2 & 10.2 & 10.4 & 10.9 & 11.6 & 11.7 & 13.1 & 13.4 & 14.1 & 13.9 \\
\hline EU-28 & 10.2 & 10.8 & 11.4 & 12.8 & 13.1 & 14.7 & 14.8 & 15.4 & 16.2 & 16.6 & 17.7 \\
\hline \multicolumn{12}{|c|}{ Share of energy from RESs for electricity } \\
\hline Austria & 61.8 & 62.4 & 62.4 & 64.6 & 65.2 & 67.8 & 65.7 & 66.0 & 66.5 & 68.8 & 70.0 \\
\hline Germany & 9.4 & 10.5 & 11.8 & 13.5 & 15.0 & 17.4 & 18.1 & 20.9 & 23.6 & 25.3 & 28.2 \\
\hline Italy & 16.1 & 16.3 & 15.9 & 16.0 & 16.6 & 18.8 & 20.1 & 23.5 & 27.4 & 31.3 & 33.4 \\
\hline Poland & 2.1 & 2.7 & 3.0 & 3.4 & 4.4 & 5.8 & 6.6 & 8.2 & 10.7 & 10.7 & 12.4 \\
\hline EU-28 & 14.4 & 14.9 & 15.4 & 16.1 & 17.0 & 19.0 & 19.7 & 21.7 & 23.5 & 25.4 & 27.5 \\
\hline
\end{tabular}

In this REJS, with an integrated use of different available instruments, the creation is proposed of a new local context to enhance awareness of the population, entrepreneurs and in- termediaries and to significantly promote the use of Renewable Energy.

As the results of the analysis of the regulatory framework 
at EU, national, regional and local levels, the difficulties encountered in the past in meeting this target can partly be explained by:

- the high cost of renewable energy owing to the investment and management required;

- administrative problems resulting from installation procedures and the decentralized nature of most renewable energy applications;

- the opaque and/or discriminatory rules governing grid access;

- inadequate information for suppliers, customers and installers.

Furthermore in the countries participating to the Project "Cities on Power" the externalities have not been taken into account and this gives to fossil fuels an artificial advantage.

Figure 2 shows how biomass is the principal RES used for energy production. The extent to which other energy sources have been developed varies considerably depending on the type of source and on the country. As shown in Table 1, an assessment of the share of RES in the energy mix and the progress made in the last years, shows that more and better could be made of RESs. Furthermore, the progress made by the Countries of the Partners has been patchy and highly uneven.

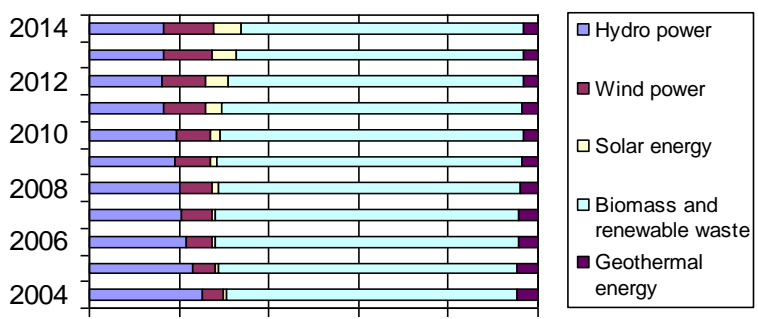

$\begin{array}{llllll}0 \% & 20 \% & 40 \% & 60 \% & 80 \% & 100 \%\end{array}$

Year

Figure 2. Gross inland consumption of renewable energy by source, EU-28, 2004 - 2014 (Source Eurostat - Primary production of renewable energy by type - annual data 2015)

The delay in setting binding target and the gaps in the legal framework for RESs have meant that a real progress has only been possible for the few Countries whose determination has outweighed their changing political priorities. Additional efforts are therefore required. This REJS is an opportunity to fill the gap and to drive the introduction of RESs in the urban context.

The EU has adopted a legislation (Renewable Energy Directive [3]) including specific measures and objectives for the three following sectors: electricity, biofuels and heating \& cooling.

It is evident that the production of biofuels is hardly compatible with the urban context. Also the large power production from RESs is of difficult placement in the urban context. However, the distributed production of electric energy from RESs (photovoltaics, micro-wind) is fully compatible with the urban context and can give a real contribution to the increase of the share of energy from RESs. This contribution can increase if this distributed electricity production is coupled to intelligent energy distribution systems (smart grids).

The EU Commission [7] is of the opinion that the "Heating and cooling" sector, which accounts for approximately $50 \%$ of final energy consumption, is not doing enough to exploit the potential of RESs. As shown in Table 1, the share RESs used in this sector is rising only slowly.
The main barriers against a stronger uptake of Renewable Energies in the "Heating and cooling" sector are individuated in:

- costs or lack of financial support,

- lack of awareness or unfavourable building regulations,

- a decentralised nature of the sector,

- split interests of some market actors, as in the case of landlords and tenants,

- a lack of a supportive tax policy, which would address the issue of cost competitiveness,

- a lack of education and training for installers to ensure a sufficient number of qualified staff,

- a political attention too much focused on the electricity, not focused on the size and potential of the "Heating and cooling" sector.

The Renewable Energy Directive [3] sets an overall mandatory target for the proportion of Renewable Energy figuring in gross domestic consumption by 2020 and provides, for each Member State, the adoption of mandatory targets and action plans in line with the potential. Setting targets at European level makes it possible to ensure that national and local policies on this issue remain relatively stable.

\subsection{Renewable energy in cities and towns}

International Energy Agency in a specific chapter of the World Energy Outlook 2008 [8] analysed first the size and pattern of the energy consumption in the world's cities and towns and the projected developments through to 2030. Actually, this is the most detailed analysis of the city energy use and is updated to 2006 .

According to IEA's World Energy Outlook 2008, in 2006, $67 \%$ of global energy (7900 Mtoe) was used in urban areas, and cities were responsible for $76 \%$ of energy related $\mathrm{CO} 2$ emissions. The average annual growth rate was predicted to be around 2\% during the period 2006-2030. In the European Union, characterised by high levels of population density, urbanisation and energy use, $69 \%$ of global energy was used in urban areas, in front of an urbanisation rate of $73 \%$. A higher share of grid-based fuels, such as gas, heat and electricity, was consumed in cities, compared with the EU average for all fuels, whereas a lower proportion of coal, biomass and oil was used.

The proportion of global energy consumed in cities is much higher than the share of the population living in cities. This is because city energy use is related to economic activities, as well as city population. A large proportion of industrial and commercial activities, which consume a large proportion of total energy, is located in the cities. Urban energy use is also higher than rural energy use, because per-capita energy use tends to be significantly higher in cities than in rural areas.

Cities consumed $82 \%$ of total annual natural gas use, $76 \%$ of nuclear, $76 \%$ of coal, $75 \%$ of hydro, $72 \%$ of the other RESs and $63 \%$ of oil (since a high proportion of transport is outside of cities). Conversely, only $24 \%$ of biomass was consumed in cities since this resource was mainly used for traditional cooking and heating in rural areas. Around $76 \%$ of total electricity generation was consumed by city dwellers. The share of natural gas and electricity consumed in cities was higher than the average of all fuels due to the more extensive infrastructure for energy distribution and higher applianceownership rates in developing cities relative to rural areas.

The spatial density of energy demand within city urban areas typically ranges between 10 and $100 \mathrm{~W} / \mathrm{m}^{2}$ of land area [9]. This parameter is influenced by population density and 
average income.

The spatial density of energy production resulting from the collection and end use of many renewable energies typically varies between:

- 0.5 and $1 \mathrm{~W} / \mathrm{m}^{2}$ for wind and biomass;

- 10 to $30 \mathrm{~W} / \mathrm{m}^{2}$ for solar.

No data are given for low temperature geothermal applications and in particular for the Ground Source Heat Pumps, the most promising technology [10]. By considering the average availability of soils and the typical productivities, we can estimate that the spatial density of energy production can be one order lower than that of solar energy.

It is evident that the high energy densities of some urban areas would require large areas of collection outside of the city boundary if renewable energy is to be used to increasingly supply the energy needs within the boundaries of the cities.

In this sense, in the near future one energy carrier that can help in providing city consumers with greater and differentiated energy access, in particular from Renewable Energy, is recognized in electricity. Also District Heating and Cooling can became a useful and easy way to introduce Renewable Energy in the cities.

However, even though energy densities of RESs are relatively low, the resources available within the cities boundaries $[11,12]$, with other collectors located on nearby land, can usually be sufficient to make a significant contribution to the total energy demand.

\subsection{Local authorities}

In an energy strategy, in particular in a Renewable Energy strategy, the role played by the local authorities is of particular relevance, as evidenced also by the European Union in the "2020 Energy Strategy" [13]. The reasons are different and shortly discussed in the following. For further details see for instance $[14,15]$

The Local authorities are responsible, in many EU countries, for the policy areas strictly linked to the Renewable Energy development, such as education and training, entrepreneurship, labour market, infrastructure or energy efficiency.

Local authorities can have an active role in spreading the use of energy generated by using RESs, by promoting local campaigns to inform citizens about the advantages, by demonstrating that renewable energy production can be both sustainable and economical.

Local authorities can also develop pilot projects to show the benefits of renewable energy, or to test new energy conversion technologies with a view to improving the green technology sector. The involvement of the local authorities in the Renewable Energy market can attract investors and spur private investments towards the green economy.

Local authorities can carefully assess their local energy demand and supply, in order to drive to the most advantageous RESs and conversion technologies. This is particularly relevant with RESs, because they are decentralized in nature and with an availability variable from place to place.

Local authorities can also have an important role in orienting the national vision on the local context and at the same time to bring the priorities of the Renewable Energy closer to the people, strengthening the feeling of ownership needed to get everyone involved, in moving towards the renewable energy targets.

There is a strong need of coordination, because the large diversity of activities proposed by different local authorities might point into uncoordinated directions, with a consequent difficulty in identifying national energy targets in the renewa- ble energy field. This need of coordination is important also at the trans-national level, in order to make that the experience gathered by a local authority could be used by other local authorities.

\subsection{Activities to promote Renewable Energy}

Due to the transnational composition of the Partners group in the Project "Cities on Power", the REJS cannot follow a "target setting" policy, because this is demanded to each Partner with his Local Action Plan. For this reason the base of this REJS is an organized list of suggestions and a clear discussion of the items that in the introductory analyses were recognized by the different Partners as the elements useful to increase the share of Renewable Energy use in the cities.

In general terms, the measures proposed in this REJS try to increase the internal market and remove the barriers to developing renewable energy in the sectors "Heating and cooling" and "Electricity production" by, for example, reducing the administrative burden, improving transparency and provision of information, and adjusting and increasing the number of pilot installations.

The Renewable Energy Joint Strategy, when translated into the Local Action Plans, will encourage an optimal use of the existing financial instruments, as well as other instruments focused on supporting research and disseminating technology. Local and regional authorities are at the right level to encourage the maximum use of the instruments available and to promote the development of Renewable Energy Sources, e.g. through administrative simplification and improved planning.

Moreover, alternative energy sources to fossil fuels will help guarantee security of energy supply in the European Union and on local level and reduce the energy bill resulting from increases in the price of fossil fuels. Furthermore, by developing the technologies for the renewable energy sector will create new business opportunities, particularly for exporting these technologies. It is also expected to have a positive impact on employment and gross domestic product growth.

After analyzing the above mentioned facts the Partners of the project "Cities on Power" agree that the relevant elements to be endorsed in a Local Action Plan should be summarized as the following points:

1) clear targets and appropriate legislation,

2) availability of mature technologies appropriate in the local context,

3) opening and support to the innovation,

4) R\&D program to enhance capacity and competitiveness of industry and to assure the feasibility of the targets,

5) competitive markets to control the price trends and active presence of the local administration on the market to prevent economic distortions and inefficient energy consumption,

6) market enhancement and infrastructure development,

7) appropriate financial instruments to support the RES utilization and production,

8) subsidy programs, because both the technologies and the markets are not mature and competitive, respectively,

9) removal of the non-technical institutional barriers to the wide spread utilization of RE,

10) information and dissemination for a higher level of awareness,

11) opportunities for the population to participate in erection of RE plants.

The REJS addresses specifically policy makers who devel- 
op actions for renewable energy politics. Because the "Cities on Power" partner countries are very different, not all recommendations will be suitable or even necessary for all countries. Thus, policy makers choose the suggestions that are appropriate and helpful for their country's specific conditions and needs, and design local action plans that are most favourable for a competitive, sustainable and secure energy supply based on Renewable Energies.

\section{RENEWABLE ENERGY JOINT STRATEGY}

The main purpose of this REJS is to examine the conditions for a further development of renewable energy utilization. This Strategy covers the three fundamentals of EC energy policy (sustainability, security of supply and competitiveness) and is consistent with the long-term EU decarbonisation scenarios, which all point to a substantially increased share of RESs. There is the need to ensure a cost-effective development of the renewable energy potential, as well as to ensure that their further expansion could occur in line with the requirements for system stability and consistently with other EU policies, notably climate mitigation, internal market, international cooperation and technology development and protection of the environment, including biodiversity.

The REJS is detailed through the following issues:

1. General policy approach

2. Financial support

3. Administrative procedures

4. RESs in distributed power production and Smart Grids

5. RESs in Heating and Cooling and electricity

6. Sustainability

7. Regional and international dimensions

8. Technology development

9. Participation

\subsection{General policy approach}

As the general policy approach to be adopted, the following points are individuated to promote RESs:

- locally dedicated targets for RESs, mandatory if possible and based on the national regulatory framework;

- enhanced focus on R\&D, particularly to improve the quality and competitiveness of RESs within Europe;

- enhanced policies of facilitation, such as faster and easier procedures to get permits, fine-tuned and in addition to the national policies envisaged;

- public procurement obligations.

Furthermore, it is necessary to promote the following activities :

- widespread campaigns for energy auditing of public buildings,

- definition of high standards for energy efficiency and use of renewable energies for all public buildings,

- elaboration of pre-investment plans to be implemented in public projects on the basis of the locally available resources and with a priority in terms of cost-benefit analysis.

\subsection{Financial support}

The cost of RESs has been falling steadily for the last years, but remains higher than that of conventional energy sources. This is mainly due since the external costs of fossil fuels have not been internalized and thus, in terms of costs related to the environment, heath and wastes, they weigh heavily on the general community. This makes the RESs less competitive against the conventional ones [16].

For the Partners of the Project "Cities on Power", energy subsidies to the utilisation of RESs in "Heating and cooling" and "Electricity production", in accordance to the Energy Roadmap 2050 [17], continues "to be necessary beyond 2020 to ensure that the market encourages the development and deployment of new technologies and will need to be phased out as technologies and supply chains mature and market failures are resolved".

It is evident that the financial support is easily possible at the national level; however, the local level plays an important role. The Partners of the Project "Cities on Power" find necessary to guarantee as an essential point of the REJS and Local Action Plans the widespread diffusion of the information about the available schemes of financial support, the search for local resources useful to the start-up of the RESs programs, the collection and coordination of the stakeholder interested but unable, for economical reasons or for lack of structure, to participate.

\subsection{Administrative procedures}

The non-cost obstacles for a deep penetration of RESs are identified, at least for some types of intervention and in some territorial areas, in the length and complexity of administrative procedures relating to authorization, certification and licensing. Lack of commonly agreed technical specifications and lack of reliable and certified training and qualification are the other biggest obstacles seen in this category. For example, for the stakeholder involved in Renewable Energy production/utilization, the absence of clear deadlines in the authorization procedures, leading to excessive time, is stressed as a key problem.

The Partners of the Project "Cities on Power" find necessary to be called for more direct intervention into these procedures, even for harmonisation or mutual recognition in this field.

\subsection{RESs in distributed power production and Smart Grids}

In the distributed power generation, electricity is generated close to the point of consumption. This decreases the need for large electricity systems and opens wide opportunities for improvements in energy efficiency, energy usage and increased use of RESs. The Partners of the Project "Cities on Power" find necessary to promote these solutions, because they are fully compatible with the urban context.

The power production from RESs will be encouraged in those areas where intelligent energy distribution systems (smart grids) will be installed.

\subsection{RESs in Heating and Cooling and electricity}

Among the most promising pathways for the utilization of RESs in "Heating and cooling", the Partners of the Project "Cities on Power" find necessary to concentrate the activities on those technologies close to the market, like solar thermal, biomass and heat pumps. Ground source heat pumps, heating and cooling storage will be taken into account even if they need further R\&D.

\subsection{Sustainability}

The Partners of the Project "Cities on Power" find neces- 
sary to apply sustainability criteria to the development of the Local Action Plans. In particular, new specific criteria will be applied to the use of biomass to ensure that only the best performing biomass (in terms of processing and treatments, renewability and environmental impact), will be promoted and the environmental impact of their use kept to a minimum. This to make sure that in the sustainability criteria will be reflected the increased competition for the limited resource "biomass" and new aspects of land-use change.

\subsection{Regional and international dimensions}

RESs are characterized by a strong local nature (availability of sunlight, biomass, wind, geothermal resources, etc.). Therefore a stronger effort to involve RESs in a "local" energy planning is important, in order to favour the penetration of RESs utilization.

Next to this, an enhanced visibility for the different experiences grown in other countries can be useful to a faster development and promotion of RESs.

The Partners of the Project "Cities on Power" find necessary to base their strategy by planning with a major attention to local aspects and at the same time by opening their activity to national and international cooperation.

\subsection{Technology development}

The key challenges for the technologies in the area of RESs are identified in: performance, cost-competitiveness, issues linked to system integration of new technologies and industrial manufacturing, supply chain issues. The existing industrial initiatives need to move toward small-scale and local applications. Most of these topics can be managed easily at the national level. However, at the local level it could be easier to facilitate the step from basic research to applied research and to the spread of innovation and marketing. At the local level it will be easier to satisfy the need for more training and education programs linked to Renewable Energy technologies and an improvement in communication efforts to disseminate the results.

The Partners of the Project "Cities on Power" find necessary to sustain at the local level the technology development in order to promote the utilization of Renewable Energy Sources.

\subsection{Participation}

The participation of all stakeholders in the energy turnaround is very important for a successful implementation and also a common principle of the European Union [18]. On the one hand the public wants to play a role in decision-making and wants to be a part of the development. On the other hand the public administration is not able to overcome the major problems alone. They need resources and the commitment of local stakeholders to achieve their self appointed objectives. Therefore it is important to involve local stakeholders also in the development of climate and energy issues. It leads to more awareness and acceptance and support the decision making of investments in renewable energies. Furthermore, people get the chance to invest in renewable energy plants or infrastructure together. Cities should implement and support participation instruments in local concepts.

The Project "Cities on Power" has developed a transnational participatory concept which describes in which manner stakeholders can be involved in renewable energy utilization in urban development, under the consideration of different instruments. This concept is an offer to all European municipalities and shows, how a participatory concept could be set up and elaborated in their cities.

One aspect that must be covered in all Local Action Plans, related to the request of information and active participation of the population in the spread of renewable energies, is an effective communications and listening strategy, where the media, internet and the most popular social networks will play a fundamental role and are essential in shaping public opinion, to effectively support the strategy for energy efficiency and the spread of renewable energies.

\section{EMERGING LESSONS}

The results of the Project "Cities on Power" are showing some emerging lessons, useful in the definition of future actions for the development of the renewable energy market.

1. Promoting RESs can become a natural continuation of the sustainability policies already started (typically the Local Agenda 21 programs), that already produced an increase in understanding and awareness in energy utilization. It is useful to look for a continuity with the existing programs by moving now the focus from energy efficiency to renewable energy.

2. The pilot actions of the local authorities can have a strong positive promotion effect; then other local authorities can follow. These "model cities" can become significant for a city-to-city transfer of information and motivation.

3. European and national energy policies can create the enabling conditions for a further development of RESs. Such conditions could be national or state targets for renewable energy, incentive programs, funds for demonstrations, electric utility policies like feed-in tariffs, competitions and awards, or funding for urban development that explicitly incorporates renewable energy. However, it is at the local level that effects and results of these enabling conditions can be verified and measured and therefore it is important to stress the role played by the local authorities.

4. Information and demonstration centres for renewable energy and energy efficiency are useful to provide training and expertise, and to bring together a critical mass of experts, small businesses, and stakeholders to move local innovation.

5. Participation of the whole set of stakeholders (final users, policy makers and investors) to the definition of the action plans is a key for successful results in terms of increased share of renewable energy in the cities.

\section{ACKNOWLEDGEMETS}

Work funded by Provincia di Ravenna in the frame of the Cites on Power Project.

Authors thank all the Colleagues of the CoP Project (City of Warsaw - Lead Partner; Energy Conservation Foundation Warsaw; Municipal authority of the provincial capital Klagenfurt am Wörthersee; Ecopower Stock Exchange Salzburg; Research Studios Austria Salzburg; Local Agenda 21 for Dresden; Province of Torino; Environment Park S.p.A; Province of Ravenna). Special thanks to Alberto Rebucci.

\section{REFERENCES}

[1] S. Piva and G. Casano. (2014, Nov.). Renewable Energy Joint Strategy. [Online]. Available: http://www.citieson power.eu/upload/File/3.3.3 Re- 
newableEnergyJointStrategy.pdf

[2] "EUROPE 2020 A strategy for smart, sustainable and inclusive growth", COM(2010) 2020 final, Communication from the Commission, Brussels, 03.03.2010

[3] "Directive 2009/28/EC of the European Parliament and of the Council of 23 April 2009 on the promotion of the use of energy from renewable sources and amending and subsequently repealing Directives 2001/77/EC and 2003/30/EC", Official Journal of the European Union, Vol. 52, 5 June 2009, pp. 16-62

[4] 30 Energy Cities' proposals for the energy transition of cities and towns, Energy Cities, 2014. [Online]. Available:

http://www.energycities.eu/IMG/pdf/cahier_short jan2014 en.pdf

[5] J. O. Lewis, S. Ní Hógáin and A. Borghi. "Cities of Tomorrow - Action Today. URBACT II Capitalisation. Building energy efficiency in European cities", URBACT, May 2013. [Online]. Available: $\mathrm{http} / / /$ urbact.eu/sites/dfault/files/import/general_library /19765 Urbact WS6 ENERGY low FINAL.pdf

[6] Global Status Report on Local Renewable Energy Policies - A Collaborative Report by: REN21, ISEP, ICLEI - Local Governments for Sustainability, 2011. [Online]. Available: http://www.ren21.net/Portals/0/ docu-

ments/Resources/REN21_Local_Renewables_Policies 2011.pdf

[7] "Renewable Energy: Progressing towards the 2020 target", $\operatorname{COM(2011)~} 31$ final, Communication from the Commission to the European Parliament and the Council, Brussels, 31.1.2011

[8] "Energy Use In Cities" in World Energy Outlook 2008, International Energy Agency (IEA), OECD/IEA, 2008, ch. 8. [Online]. Available: http://www.world energyoutlook.org/media/weowebsite/20081994/weo2008.pdf

[9] Cities, towns \& Renewable Energy - Yes In My Front Yard, International Energy Agency (IEA), OECD/IEA, 2009. [Online]. Available: http://www.iea.org/publica tions/freepublications/publication/cities2009.pdf
[10] S. Lo Russo, C. Boffa, M. V. Civita. (2009). Lowenthalpy geothermal energy: An opportunity to meet increasing energy needs and reduce $\mathrm{CO} 2$ and atmospheric pollutant emissions in Piemonte, Italy. Geothermics, vol. 38, no. 2, pp. 254-262. DOI: 10.1016/j.geothermics.2008.07.005.

[11] SDH Solar District Heating, "Ranking List of European Large Scale Solar Heating Plants". [Online]. Available: http://www.solar-district-heating.eu /ServicesTools/Plant database.aspx

[12] C. Delmastro, G.a Mutani, L. Schranz and G. Vicentini G., "The role of urban form and socio-economic variables for estimating the building energy savings potential at the urban scale," Int. J. Heat \& Technology, vol. 33, pp. 91-100. DOI: 10.18280/ijht.330412.

[13] European Commission, "Europe 2020 Who does what: Regional and local authorities". [Online]. Available: http:/ec.europa.eu/europe2020/who-does-what/ regional-and-local-authorities/index_en.htm

[14] G. Comodi, L. Cioccolanti, F. Polonara and C. Brandoni., "Local authorities in the context of energy and climate policy," Energy Policy 51, pp. 737-748, 2012. DOI: $\underline{10.1016 / j . e n p o l .2012 .09 .019 .}$.

[15] C. Brandoni, F. Polonara. (2012). "The role of municipal energy planning in the regional energy-planning process," Energy, vol. 48, pp. 323-338. DOI: 10.1016/j.energy.2012.06.061.

[16] "Renewable energy road map renewable energies in the 21st century: building a more sustainable future" $\operatorname{COM}(2006) 848$ final, Communication from the Commission to the European Parliament and the Council, Brussels, 10.01.2007.

[17] European Commission, "Energy Roadmap 2050" $\operatorname{COM}(2011) 885$ final, Communication from the Commission to the European Parliament, the Council, the European Economic and Social Committee and the Committee of the Regions, Brussels, 15.12.2011

[18] "The European Consensus on Development" (2006/C 46/01) Official Journal of the European Union, pp. C46/1-19, 24.02.2006. 